\title{
Toward a unified model of mobile Business Intelligence (m-BI) acceptance and use
}

\author{
Paweł Weichbroth $\bowtie$ \\ Gdansk University of Technology \\ Department of Software Engineering \\ pawel.weichbroth@pg.edu.pl
}

\author{
Jolanta Kowal \\ University of Wrocław \\ Institute of Psychology \\ jolanta.kowal@uwr.edu.pl
}

\author{
Mateusz Kalinowski \\ Meritus Systemy Informatyczne \\ Artificial Intelligence Department \\ mateusz.kalinowski@meritus.pl
}

\begin{abstract}
Factors affecting mobile business intelligence ( $m-B I)$ acceptance and use have become an increasingly important topic in practice due to the growing complexity of organizations, and their underlying information systems (IS). Since, one can notice considerable interest in $m-B I$, however, to the best of our knowledge few studies (if any) aim to synthesize the existing body of knowledge with regards to the factors affecting m-BI acceptance and use. To fill this gap, we conducted a systematic literature review and summarized the current state of the art. By addressing research questions, we identified a set of five factors, namely: Perceived Value, Perceived Ease of Use, Managerial Attitudes, Facilitating Conditions and Quality of Information, and specified their inter-relationships. Moreover, we introduce an acceptance model (m-BIAM) on behavioral intention and use mobile Business Intelligence solutions. The contribution of this study lies in these evidence-based findings, which lay a solid foundation for further studies in the extent of testing and evaluating the m-BIAM model, targeted at delivering more evidence to confirm its validity and predictive power.
\end{abstract}

\section{Introduction}

The global Business Intelligence (BI) market is predicted to grow from $\$ 23.1$ billion in 2020 to reach $\$ 33.3$ billion by 2025 , with a Compound Annual Growth Rate (CAGR) of $7.6 \%$ during the forecast period [1]. Similarly, the size of the mobile BI (m-BI) market is foreseen to progress from $\$ 10.08$ billion in 2019 to $\$ 17.18$ billion in 2025 , at a CAGR of $22.2 \%$ during the outlook period [2]. The reasons for m-BI growth concern both hardware and software developments. While the former concerns the growing adoption of the Enterprise Mobile Application Platforms, often connected with the integration of Internet-of-Things (IoT) technologies, the latter is the result of strong competition between BI vendors. Moreover, it is worth noting here, that nowadays, while the global pandemic is having a devastating impact on public health, and caused an economic crisis around the world, then cloud and mobile computing are claimed to be an unsung hero in the battle against the COVID-19 $[3,4,5]$.

From the research perspective, m-BI has imposed new challenges, opportunities and issues to be studied. In 2012, O'Donnell et al. [6] placed mobile business intelligence on the top of the list, regarding critical issues facing business intelligence practitioners at the current time. Security [7], privacy [8], usability [9] and availability [10], to name just a few, undoubtedly are the ones that must be fulfilled for m-BI to be placed on the market shelf. Here, a question arises: what other factors influence mobile BI acceptance and use?

On the other hand, mobility is no longer considered a "nice to have" option, it's rather a must for plenty of businesses. Therefore, the decision-makers face the challenge of selecting and implementing the m-BI solutions, keeping in mind their specific hardware limitations (e.g. connectivity, screen size), as well as employee (users) expectations and requirements. Until now, various models have been demonstrated and evaluated to aid understanding of drivers behind the acceptance and use of m-BI solutions.

However, to the best of our knowledge, there are few studies (if any) that synthesize and classify the state-of-the-art research in this area. Toward that end, we employ a qualitative mixed-method approach, combining systematic literature review, survey, and semi-structured interviews with experts. Using different sources of information, a multi-faceted analysis enabled us to reflect upon both the theory and practice. As a consequence, having timely and reliable primary and secondary data, we developed the classification of the factors and assembled a unified model of the user acceptance of m-BI technology.

The rest of the paper is structured as follows. Section 2 provides the theoretical background and motivation. Section 3 gives an overview on the methodology 
applied. Section 4 introduces the m-BIAM model from the study conducted, followed by the discussion in Section 5. Eventually, Section 6 outlines the final conclusions.

\section{Background and Motivation}

In the light of recent studies, regarding both BI and m-BI, we firstly draw upon the theory, and secondly, we discuss the current issues and challenges. Therefore, this section provides a brief synthesis of both past and ongoing research efforts in these two areas, outlining the theoretical framework and genesis of the current study.

Nowadays, Business Intelligence (BI), previously also known as Business Analytics (BA), is developing intensively. The term has been used by scientists dealing with artificial intelligence since the 1950s. For instance, in 1958, H. P. Luhn identified BI with data analysis tools [15]. However, it did not become a popular term in business and IT environments until the 1990s.

At the end of the 20th century, BA was introduced as a key analytical component of BI [16, 17]. Currently, the authors differentiate BA from BI which analyzes past and present data to efficiently handle current operations, while BA analyzes past data to analyze current scenarios and prepare for companies' future [18]. BA as a system based on machine learning techniques is also intensively developing to promote the organization's effectiveness and efficiency by supporting the decision-making process. It applies not only to specific areas of the company but also to various sectors of the economy.

$\mathrm{BI}$ is the process of transforming data into information, and information into knowledge that can be used to increase the company's competitiveness [19]. In the business sense, it means a combination of system architecture, applications, and databases that enable real-time analyses and transformations, providing the necessary information and knowledge to business [20], and comprising the strategies and technologies used by establishments to analyze business information. BI capabilities enable reporting, analytics, online analytical processing, dashboard creation, data mining, processes, complex event processing, business performance management, benchmarking, text mining, predictive analytics, and predictive analytics [21, 22].

Some modern conceptualizations present BI as a strategic artifact in four strategic clusters: as a system, as a planned process, as a product, and as a decision paradigm. Organizations need data obtained through BI to influence how their company operates and responds to the changing market [23]. In a purely business and practical sense, BI is a combination of system architecture, applications, and databases that together enable real-time analysis and transformation, providing the necessary information and business knowledge [24]. The basic tools of each analyst are the equivalents of a sheet of paper and a pen, text editor, modeling tools, versioning tools, equivalents of whiteboard and sticky notes (e.g. calendar), spreadsheets, data presentation and visualization programs.

The new challenge is mobile Business Intelligence (mobile BI, or m-BI) which means a system composed of technical and organizational elements that provide users with historical or real-time information. Information is analyzed on mobile devices such as smartphones and tablets, enabling real-time decision-making and management support to increase the company's efficiency. Table 1 depicts five selected definitions of mobile BI.

The intensive development of mobile data processing is due to ideas that have been popular for over ten years, especially due to the transition from the "wired world" to the "wireless world". An important factor in this process is the preponderance of smartphones, which ushered in the era of mobile computing in the BI field [25]. The interest in and exploration of mobile technologies is constantly growing, especially in developing countries, where $\mathrm{m}$-BI serve the needs of customers and the expectations of stakeholders. Mobile BI applications are claimed to be a source of accurate and timely information for the decision-makers [26]. The current m-BI solutions include: Fivetran, Tableau, Domo, and Power BI Mobile. To date, leaders in analytics and BI platforms are Microsoft, Tableau, Qlik, SAP, and Sisense [27].

Striving for effective BI has been a long-standing aim of firms in different sectors of industry [28, 29]. This is evidenced not only by considerable investments made, but also by the corresponding proliferation of research. Nevertheless, many studies have reported failures of BI implementations, understood in terms of the lack of user satisfaction. For instance, Isik et al. [30] reported that fewer than $25 \%$ of users declared being strongly satisfied with any aspect of their BI solution, indicating they are not yet getting full leverage from $\mathrm{BI}$ in terms of timeliness, precision, decision-making support, or even ease of use that they seem to expect.

Concerning acceptance of the BI solutions, other studies point to factors such as user participation in the implementation of the system [31], users' motivation to learn [32] According to Motta et al., the most significant drivers behind m-BI implementation include [33]: integration of existing BI systems and increasing their usability, as well as improving business efficiency and information communication timeliness. Moreover, Dubravac and Bevanda reported that users' 


\begin{tabular}{|c|c|c|}
\hline Id & Definition & Author(s) \& Year \\
\hline 1 & $\begin{array}{l}\text { m-BI applications are extension of the BI functionalities on mobile devices used } \\
\text { by the decision makers in companies and classify this type of applications in three } \\
\text { categories: "standalone applications (they run on mobile devices independently } \\
\text { of external resources and connections), network applications (they use distributed } \\
\text { components on mobile devices as well as on external systems) and web applications } \\
\text { (they run only the interface of the mobile device, while the application uses external } \\
\text { application servers)". }\end{array}$ & $\begin{array}{l}\text { Trif \& Visoiu, } \\
2011[11] .\end{array}$ \\
\hline 2 & $\begin{array}{l}\mathrm{m} \text {-BI is not a standalone solution, but a complementary solution to traditional BI, } \\
\text { providing users with self-service, efficiency, and the mechanism to make real-time } \\
\text { decisions using organizational data that is readily available. }\end{array}$ & $\begin{array}{l}\text { Tona \& Carlsson, } \\
2013 \text { [12]. }\end{array}$ \\
\hline 3 & $\begin{array}{l}\mathrm{m}-\mathrm{BI} \text { is a capability that enables the mobile workforce to gain business insights } \\
\text { through information analysis using applications optimized for mobile devices. }\end{array}$ & $\begin{array}{l}\text { Verkooij \& Spruit, } \\
2013 \text { [7]. }\end{array}$ \\
\hline 4 & $\begin{array}{l}\mathrm{m} \text {-Bi is the ability of the persons to access BI related data such as dashboards, key } \\
\text { performance indicators, and business metrics, on mobile devices. }\end{array}$ & $\begin{array}{l}\text { Alexe et al., } 2014 \\
\text { [13]. }\end{array}$ \\
\hline 5 & $\begin{array}{l}\mathrm{m} \text {-BI is the ability to access BI-related data such as key performance indicators (KPIs), } \\
\text { business metric and dashboard through mobile device; } \mathrm{m} \text {-BI addresses the use-case of } \\
\text { remote or mobile workers that need on-demand access to business-critical data. }\end{array}$ & $\begin{array}{l}\text { Fang et al., } 2018 \\
{[14] \text {. }}\end{array}$ \\
\hline
\end{tabular}

Table 1: The selected definitions of the Mobile Business Intelligence.

future expectations from adopting m-BI concern [34]: additional education/ training using BI systems and analytics tools, frequently updated data, upgrading data infrastructure for scalability and availability, richer self-service functionality, access to data warehouses, and the increase of BI use and data services in the cloud.

Last but not least, in our humble opinion, timely and effective conversion of data and information into working knowledge, at any time and in any place, is a major contributor to competitive advantage which can be accomplished by using $\mathrm{m}-\mathrm{BI}$ solutions. The rationale behind this claim is that $\mathrm{m}-\mathrm{BI}$ inherits most (if not all) advantages of BI tools, which bring the advantage over competitors by analyzing market trends, identifying the profitable customers, enhancing decision-making abilities [20, 35, 36], just to name a few. While numerous scholars have expended efforts to examine the topic of m-BI, research in this field still remains fragmented, making it difficult to gain a comprehensive understanding of the current state-of-the-art and to forge a path ahead. This study aims to fill this gap and to develop a theoretical model using a multidisciplinary approach that draws upon the literature.

\section{Methodology}

Our study is qualitative by nature and is based on the review and analysis of available secondary data. Therefore, we selected the Systematic Literature Review (SLR), as the most appropriate research method for extracting the body of scholarly literature. Nowadays, this method has been widely adopted in the computer science research area, enabling an evidence-based evaluation and synthesis of an emerging yet already diverse topic. In this study, we adopted guidelines suggested by Kitchenham [37], since their value has been widely acknowledged worldwide. In the following section, we provide details of their application and adaptation to the research goal.

\subsection{Research Design}

While neither BI nor m-BI are novel concepts or brand-new technologies, the latter seems to be still uninvestigated in the context of user's acceptance and use. Therefore, this research aims to develop a unified m-BI acceptance model (m-BIAM). Having said that, we set up a context of our study, necessary to formulate the research questions.

First and foremost, one should note that through this paper three terms are used alternately to denote the same concept, namely: use, acceptance and adoption. This is the result of the pilot study, which concerns selected landmark studies, regarding business intelligence models. Since our intention is not to deliberate on which of these three terms are the most suitable, we treat them as synonyms of one theoretical construct.

Research Question Definition. At the first stage of the review, the research questions should be unambiguously spelled out as a goal to be answered. Along this line of reasoning, the following research question guided the development of the research protocol: (RQ1) what are the variables used to develop 


\begin{tabular}{|c|c|c|c|c|c|c|c|c|c|c|c|}
\hline \multirow{2}{*}{ Search Query / Data Source / Step } & \multicolumn{3}{|c|}{ Scopus } & \multicolumn{3}{|c|}{ WoS } & \multicolumn{3}{|c|}{$\mathbf{A C M}$} & \multicolumn{2}{|c|}{ G. Scholar } \\
\hline & I & II & III & I & II & III & I & II & III & $\mathbf{I}^{*}$ & III \\
\hline mobile + "business intelligence" + use & 84 & 84 & 6 & 41 & 12 & 1 & 88 & 88 & 0 & 48900 & 1 \\
\hline mobile + "business intelligence" + acceptance & 2 & 0 & 0 & 4 & 0 & 0 & 74 & 0 & 0 & 26300 & 0 \\
\hline mobile + "business intelligence" + adoption & 6 & 0 & 0 & 7 & 1 & 0 & 64 & 0 & 0 & 33600 & 1 \\
\hline Sum & 92 & 84 & 6 & 52 & 13 & $\mathbf{1}$ & 226 & $\mathbf{8 8}$ & $\mathbf{0}$ & 108800 & 2 \\
\hline
\end{tabular}

I: number of the search results; II: number of the search results after duplicates removal; III: number of the relevant papers.

Table 2: The summary of the data extraction stage.

m-BI acceptance models?, and (RQ2) what are the moderators and through which relationships do they operate to impact on dependent variables?

Data Source and Search Strategy. The search process encompassed the following four databases (see Table 2). The first was the Scopus database, as the largest abstract and citation database of peer-reviewed literature [38], server as the reference point for the other three. The second was the Web of Science (WoS), being the world's most trusted publisher has indexed over 171 million records so far [39]. The ACM Digital Library (ACM) was the third database, having one of the most comprehensive collections of full-text articles covering the fields of computing and information technology, with the estimated size of 231000 distinct titles [40]. The last data source was Google Scholar, by many claimed to be the number one go-to information source in academia [41], with an estimated index of around 160-165 million documents in 2015 [42].

Search Query Definition. Keywords for the literature search were derived from the research goal. Following the database's guidelines regarding the use of Boolean operator AND, and appropriate quotation marks for a fixed sequence of terms, we used two topic terms ("mobile", + "business intelligence"), in conjunction (+) with one of the contextual terms ("use", OR "acceptance", OR "adoption"). Eventually, three separate search queries were defined (see Table 2). These search queries were executed on April 2021.

Inclusion and Exclusion Criteria. The following inclusion criteria (IC) were established to identify studies that are relevant to obtaining answers to the defined research questions: (IC1) the document type is a peer-reviewed journal article, and (IC2) the document is written in English. The first column (I) in Table 2 depicts the number of the search results, after applying together IC1 and IC2. In the case of Google Scholar, these two criteria were not applicable $\left(^{*}\right)$.

We then removed duplicates, comparing the search results separately for each query with the simultaneously updated list of papers, which eventually left us with 185 unique papers (84 from Scopus, 13 from WoS, and
88 from ACM). In this extent, the precise numbers are given in the second (II) column in Table 2 for each data source. We excluded Google Scholar from this procedure since we had to compare in total about $108 \mathrm{k}$ records.

To identify studies relevant to the focus of this review, the titles and abstracts of the extracted 185 records were screened and analyzed in-depth by two researchers, following two exclusion criteria: (EC1) the full version of the document is not available through subscription from the institutions, or from the associations of which we are members, and (EC2) the document does not exhibit a model of mobile business intelligence acceptance, use, or adoption. However, in the case of Google Scholar, we screened titles of the documents from the first thirty pages for each query $(900$ records), applying the exclusion criteria.

Eventually, the third (III) column in Table 2 shows the number of the relevant papers identified, in total standing for 9 records ( 6 from Scopus, 1 from WoS, and 2 from Google Scholar).

\subsection{Data Extraction and Analysis}

A data extraction form was developed using a document, available online for the authors, including the selected information attributes relevant to the research questions, as well as potential future studies. The extraction document included, for instance, names of authors, document title, year of publication, journal title, theory used, research method used, and the set of variables used in the particular research models, and their level of significance.

In total, 32 variables were extracted from the nine papers (see Table 3). Afterwards, the collected data set was then analyzed retrospectively. While taking into account the nature of the studied problem, and more specifically the research questions addressed, we then distinguished the following three categories of variables, used to assemble the models regarding the $\mathrm{m}-\mathrm{BI}$ acceptance:

1. Independent $(x)$ variable provides information 


\begin{tabular}{|c|c|c|c|c|c|c|c|c|c|}
\hline Code & Factor \& Reference & [14] & {$[43,44]$} & [45] & [46] & [47] & {$[48]$} & [49] & {$[50]$} \\
\hline PV & Perceived value & $\bullet$ & & & & $\bullet * * * *$ & $\bullet$ & & \\
\hline PEOU & Perceived ease of use & $\bullet$ & & $\bullet * * *$ & & $\bullet * * * *$ & • & & \\
\hline TRUST & Trust & $\bullet$ & & & & & $\bullet$ & & \\
\hline PEOA & Perceived ease of adoption & - & & & & & - & & \\
\hline TPS & Top management support & & $\bullet *$ & & & & & & \\
\hline ME & Management expectations & & $\bullet *$ & & & & & & \\
\hline ISP & Information security policy & & •* & & & & & & \\
\hline$\overline{\mathrm{UP}}$ & User privacy & & $\bullet *$ & & & & & & \\
\hline GR & Government regulations & & $\bullet *$ & & & & & & \\
\hline LAG & Loans and grants & & $\bullet *$ & & & & & & \\
\hline MP & Mobile platform & & $\bullet *$ & & & & & & \\
\hline GUI & Graphical user interface & & $\bullet *$ & & & & & & \\
\hline IU & Information utilisation & & $\bullet *$ & & & & & & \\
\hline FOI & Flow of information & & $\bullet *$ & & & & & & \\
\hline $\mathrm{SC}$ & Storage capacity & & $\bullet *$ & & & & & & \\
\hline TS & Training session & & •* & & & & & & \\
\hline VTL & Vendors/ technicians location & & •* & & & & & & \\
\hline ACES & Accessibility & & & $\bullet * * *$ & & & & & \\
\hline ATRA & Attractiveness & & & $\bullet * * *$ & & & & & \\
\hline FLEX & Flexibility & & & $\bullet * * *$ & & & & & \\
\hline ENGA & Engagement & & & $\bullet * * *$ & & & & & \\
\hline QOI & Quality of Information & & & & $\bullet *$ & $\bullet * * * *$ & & & $\bullet$ \\
\hline MA & Managerial Attitudes & & & & $\bullet *$ & $\bullet * * * *$ & & & \\
\hline SQ & System Quality & & & & $\bullet *$ & & & & \\
\hline$\overline{\mathrm{OC}}$ & Organization Climate & & & & $\bullet *$ & & & & \\
\hline$\overline{\mathrm{PE}}$ & Performance Expectancy & & & & & & & $\bullet * *$ & \\
\hline $\mathrm{EE}$ & Effort Expectancy & & & & & & & $\bullet * *$ & \\
\hline SI & Social Influence & & & & & & & •*** & \\
\hline FC & Facilitating Conditions & & & & & & & $\bullet * *$ & \\
\hline $\mathrm{AU}$ & Analytics Use & & & & & & & & - \\
\hline DVU & Data Visualization Use & & & & & & & & $\bullet$ \\
\hline $\mathrm{DU}$ & Dashboard Use & & & & & & & & $\bullet$ \\
\hline
\end{tabular}

The level of significance reported in the aforementioned studies: $* p<0.1, * * p<0.05, * * * p<0.01, * * * * p<0.001$.

Table 3: The summary of the extracted variables regarding m-BI use, acceptance, or adoption.

on an associated dependent variable $(y)$ regarding a particular outcome; by definition, each independent variable implies causality which means affecting the dependent variable.

2. Moderator $(m)$ variable affects the strength of the relationship between a dependent and independent variable. The moderator variable, if found to be significant, can cause a weakening or amplifying effect between $x$ and $y$.

3. Dependent $(y)$ variable is the effect, and its value depends on changes in the independent variable(s).

Accordingly to the above categories, we elaborated the quality criteria for each group. Next, we analyzed again and evaluated the volume of 32 extracted variables by applying the following quality criteria: must have its roots in grounded information systems theory models of technology acceptance (Q1), and must occur at least one in the relevant sources (QC2).

This procedure was performed during the online discussion between two of the authors. Since we agreed with the outcome, we also individually sought to examine the definition of each variable to check its causality with the dependent variable. Eventually, we came to a consensus on this, most notably merging and choosing four independent variables:

1. Perceived Value (PV), according to TAM 
and UTAUT models, known as Perceived Usefulness (PU) and Performance Expectancy $(\mathrm{PE})$, respectively.

2. Perceived Ease of Use (PEOU), defined as Effort Expectancy (EE) in UTAUT model

3. Managerial Attitudes (MA), in UTAUT defined as Social Influence (SI)

\section{Facilitating Conditions (FC).}

Yet, the extracted list (Table 3) shows variables (factors) specific for mobile business intelligence, which should be reconsidered. Most severely, mobile technologies, among many advantages, exhibit certain limitations, including battery lifespan, performance capacity, wireless network coverage and connection bandwidth limits. From a user perspective, mobile computing imposes other impediments, comparing to their desktop equivalents, such as smaller screen size, slow and error-prone typing, and "single window" view enforcement [51, 52]. All of these issues have been clubbed together under the moderating factor, defined as Quality of Information (QOI).

Moreover, according to Hayes [53], moderation analysis makes it possible to check whether the magnitude of the impact of a variable on any outcome variable of interest depends on a third variable or set of variables. Moderators are factors that determine the existence and strength of an observable relationship between variables or their absence. Therefore, we also adopt from UTAUT model three other moderators, namely: Gender (G), Age (A), and Experience (E), assuming that they are likely to individually influence the relationship between each of the four independent variables and the intention to use (see Figure 1).

Nevertheless, it should be pointed out that while some of the remaining extracted variables (Table 3) were found to be empirically and statistically verified, then others have not been confirmed yet. On this account, this lack of empirical studies indicates a void in the research, worth considering to include in future studies.

\section{The m-BI acceptance model (m-BIAM)}

Typically, acceptance is conceptualized as the result of a psychological process through which users go when deciding on a new technology [54]. Up to now, numerous models have been developed to explain and predict the intention to use (and use of) information systems. Among these, the technology acceptance model (TAM) [55] is the one that has been widely used, and by many is described as the most influential in IS theory to explore user acceptance [56].
Despite the model's novelty and acknowledged advantages, TAM has also its limitations. The first major limitation of TAM is self-reported usage, a better approach would be to employ an independent measure of actual use. Second, results obtained from empirical studies found that it explained approximately $40 \%$ of the variance in usage intentions and behavior [57].

Therefore, the elaborated mobile business intelligence acceptance model (m-BIAM) is based not only on the TAM model, but also has its foundations in succeeding TAM2 [58] and UTAUT models. Since both have stronger explanatory power than the original TAM model, the additional number of variables raises the question of parsimony. To balance the explanatory power and the model complexity we restrict ourselves not to include the additional variables, which, on the other hand, might be seen as another research gap to be addressed in future studies. Besides, we explain in detail below, how we understand the variables involved in our theoretical model.

Firstly, in our study we adopted the naming from TAM2 and TAM models respectively, that is Intention to Use (IU), and Actual Usage (AU). While the former is defined here as a measure of the strength of the user's interest to use m-BI solution in his/her daily work, then the latter, based on the current user experience in the context of his/her initial expectations [59], concerns the frequency of m-BI use, typically indicated by the number of $\mathrm{m}$-BI use and total usage duration during a working day or week [60].

Perceived Usefulness (PU) is defined as "the degree to which a person believes that using a particular system would enhance his or her job performance" [61]. It is worth noting here that the alternate construct of PU is defined as Performance Expectancy (PE). Taking into account the context of the current study, and similarly to the Technology Acceptance Model for Mobile Services (TAMMS) developed by Kaasinen [62], Perceived Value (PV) of m-BI takes the place of PU in our model.

Perceived Ease of Use (PEOU) is defined as "the degree to which a person believes that using a particular system would be free of effort" [61]. Typically, this construct has a different name, namely Effort Expectancy (EE).

Social Influence (SI) is defined as the degree to which an individual perceives that important others believe he or she should use the new system [63]. Taking into account the purpose of using $\mathrm{m}$-BI tools, it seems rationale to replace SI by Managerial Attitudes (MA), which in the current study is considered as the degree to which an individual perceives an influence and support from people such as the managers and directors of an organization to encourage the use of m-BI solutions 


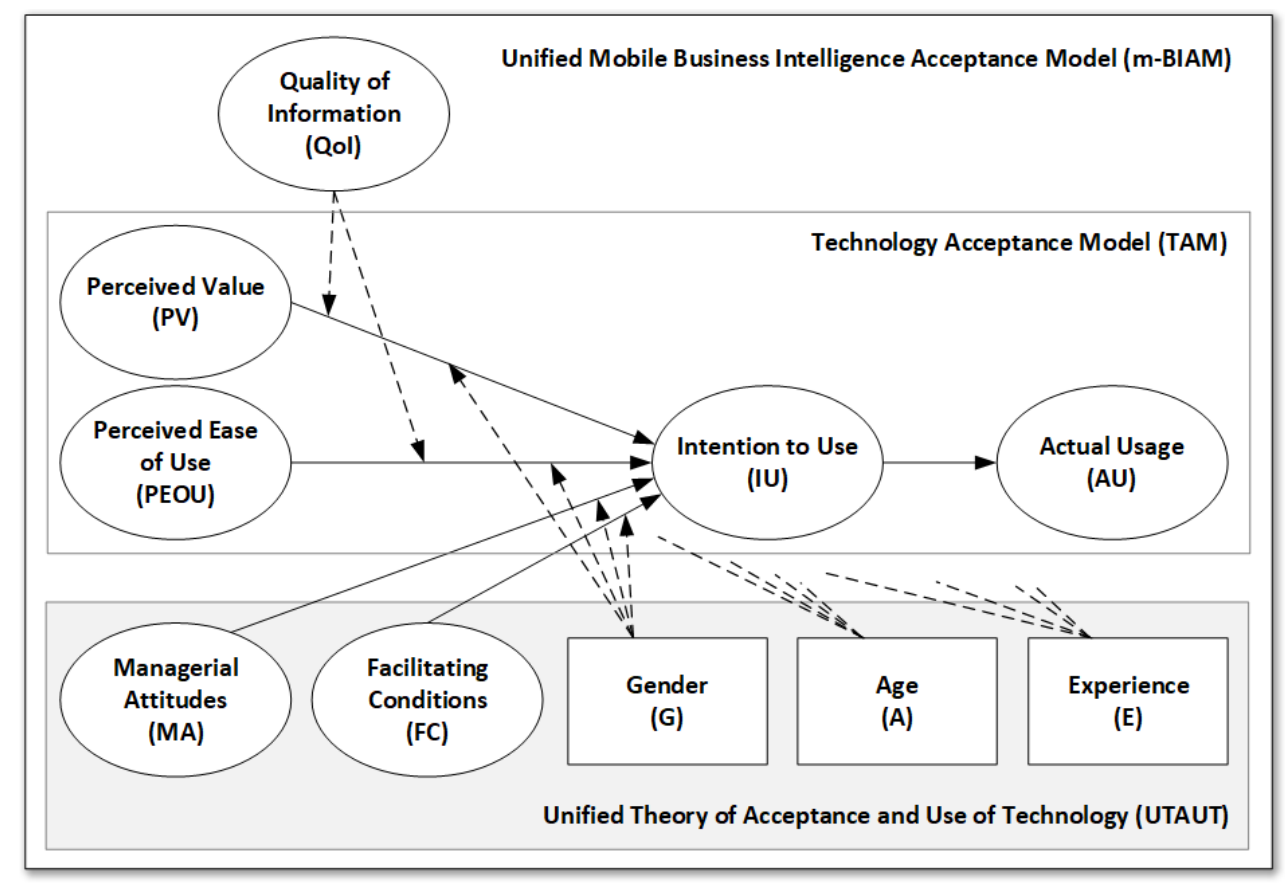

Figure 1: The unified mobile business intelligence acceptance model (m-BIAM) for business organizations.

to facilitate business processes. It is worth noting here that according to Aggarwal \& Bhargava [64], an attitude is formed in the process of satisfying needs, in certain social conditions, or a permanent organization of knowledge, beliefs, feelings, motives, certain forms of behavior and expressive reactions of a subject related to a specific object or class of objects.

Last but not least, Facilitating Conditions (FC) can be defined as the degree to which the user believes that the use of the system is supported by the existing organizational and technical infrastructure [63], including standards and guidelines [65], or technical support [66].

However, while models such as the UTAUT and UTAUT2 comprise a facilitating conditions construct, its definition, as well as its related psychometric measurements, are general and not specific to a particular technological or socio-cultural domains [67]. Moreover, to the best of our knowledge, none of the identified studies have defined and characterized the FC component with regard to the m-BI settings.

It should be also noted that the UTAUT model does not include an effect of facilitating conditions (FC) on behavioral intention (intention to use, IU) since it is expected to be non-significant [63]. While some studies confirm this assumption $[68,69,70]$, then others show the opposite [71, 72]. Since the concept of FC is seen as a relevant determinant of mobile services use [73], we expect that facilitating conditions also influence on intention to use mobile business intelligence (m-BI).

Generally speaking, Quality of Information (QOI) is defined as the degree to which information assets fulfills user's requirements, including: (i) timeliness, the speed with which information is received [74], (ii) adequacy, being enough or satisfactory for a particular purpose [75], (iii) reliability, the credibility of information resulting from past experience, source, adopted methodology for obtaining and processing information and the channel of its delivery [76], (iv) accuracy, concerning the correctness and detail of information [76], and (v) completeness, reflecting the full picture of a given realm [77].

It seems rational to conclude that the physical limitations imposed by mobile technologies can negatively impact the user's perceived effort, as well as on the perceived usefulness of the m-BI tool. Therefore, in our model, we assume that the quality of information has a moderate effect on perceived ease of use (PEOU) and perceived value (PV). More precisely, poor quality of information weakens the relationship between PEOU or PV and intention to use. Interestingly, Buchana [47] rejected the hypothesis stating that quality of information positively influences intention to use m-BI.

Figure 1 depicts the elaborated m-BIAM model, targeted at explaining users' behavioral intention to use and accept mobile Business Intelligence solutions, and 
devoted to business organizations.

\section{Discussion}

In a very short amount of time, mobile technologies have undeniably changed the way we live, and the businesses we do. The market of mobile applications has now reached a massive 8.93 million [78], while mobile business and productivity apps see 7.1 billion downloads in 2020 [79]. However, while the number of studies regarding mobile application acceptance and use has been growing every year, then the topic of mobile Business Intelligence (m-BI) has been poorly explored. This study aimed to fill this void and provide evidence-based results by employing a systematic literature review approach.

Although a rigorous and well-established methodology was used, yet the study has several limitations. First, the search procedure included the studies exclusively published in peer review journals in English and indexed by four databases. Therefore, future studies should cover papers from conference proceedings and books in English, as well other languages. Second, despite the comprehensive evaluation undertaken by the authors, including the cross-validation procedure adapted to the qualitative analysis, a bias in the interpretation of the texts cannot be excluded. Hence, more evidence is desired to confirm the assumptions and hypotheses, introduced within the elaborated m-BIAM model.

Our study contributes to the theory on information systems by delivering and assembling the m-BIAM model, explicitly identifying its internal constructs and specifying its inter-relationships. We believe that our model depicts a comprehensive view on the underlying factors affecting a user's acceptance and use of mobile business intelligence solutions, and will spark the discussion on how organizations can create economic and social value by adopting its practical tenets.

\section{Conclusions}

In this paper, we epitomize factors affecting m-BI acceptance, in particular four independent variables, namely Perceived Value (PV), Perceived Ease of Use (PEOU), Managerial Attitudes (MA), and Facilitating Conditions (FC), provide information on an associated dependent variable as Intention to Use (IU), and directly leads to the outcome - actual usage (AU). It should be noted that Facilitating Conditions (FC) have dual significance, affecting both an associated dependent and output variables. We also put forward one moderator, defined as the Quality of Information (QOI), which is assumed to affect the relationships between Intention to Use and Perceived Ease of Use (PEOU), as well as between Perceived Value (PV).

Clearly, the results give many opportunities for future research. The proposed m-BIAM model is based on interdependencies, which should be further tested and evaluated by using both qualitative and quantitative methods, in order to bring more evidence to confirm its validity and predictive power.

\section{References}

[1] Markets and Markets, "Business intelligence market by component - global forecast to 2025," 2021. Last accessed 26 May 2021

[2] Market Data Forecast, "Global mobile bi market forecast to 2025," 2021. Last accessed 26 May 2021.

[3] Z. R. Alashhab, M. Anbar, M. M. Singh, Y.-B. Leau, Z. A. Al-Sai, and S. A. Alhayja'a, "Impact of coronavirus pandemic crisis on technologies and cloud computing applications," Journal of Electronic Science and Technology, p. 100059, 2020.

[4] C. Tsinaraki, I. Mitton, A. D. Benetta, M. Micheli, A. Kotsev, M. Minghini, L. Hernandez, F. Spinelli, and S. Schade, "Analysing mobile apps that emerged to fight the covid-19 crisis," tech. rep., 2020. Last accessed 26 May 2021.

[5] B. Gawin and B. Marcinkowski, "Covid-19 lockdown and it-powered reporting: an enabler, irrelevant factor, or something in between?," in 36th International Business Information Management Association Conference, International Business Information Management Association, 2020.

[6] P. O'Donnell, S. Sipsma, and C. Watt, "The critical issues facing business intelligence practitioners," Journal of Decision Systems, vol. 21, no. 3, pp. 203-216, 2012.

[7] K. Verkooij and M. Spruit, "Mobile business intelligence: key considerations for implementations projects," Journal of Computer Information Systems, vol. 54, no. 1, pp. 23-33, 2013.

[8] C. Screen, "Best practices in mobile business intelligence," 2014. Last accessed 26 May 2021.

[9] BI-Survey.com, "Mobile business intelligence: What it is and how it works," 2021. Last accessed 26 May 2021.

[10] D. Airinei and D. Homocianu, "The mobile business intelligence challenge," Economy Informatics, 2010.

[11] S. Trif and A. Visoiu, "A windows phone 7 oriented secure architecture for business intelligence mobile applications," Informatica Economica, vol. 15, no. 2, p. 119, 2011.

[12] O. Tona and S. A. Carlsson, "The organizing vision of mobile business intelligence," 2013.

[13] C. M. Alexe, C. P. Simion, C. G. Alexe, et al., "Business intelligence-past, present and future," Network Intelligence Studies, no. 3, pp. 7-14, 2014.

[14] L. Y. Fang, N. F. M. Azmi, Y. Yahya, H. Sarkan, N. N. A. Sjarif, and S. Chuprat, "Mobile business intelligence acceptance model for organisational decision making," Bulletin of Electrical Engineering and Informatics, vol. 7, no. 4, pp. 650-656, 2018. 
[15] M. Anandarajan, A. Anandarajan, and C. A. Srinivasan, Business intelligence techniques: a perspective from accounting and finance. Springer Science \& Business Media, 2012.

[16] T. H. Davenport et al., "Competing on analytics," Harvard business review, vol. 84, no. 1, p. 98, 2006.

[17] H. Chen, R. H. Chiang, and V. C. Storey, "Business intelligence and analytics: From big data to big impact," MIS quarterly, pp. 1165-1188, 2012.

[18] D. Power, C. Heavin, J. McDermott, and M. Daly, "Defining business analytics: an empirical approach," Journal of Business Analytics, vol. 1, no. 1, pp. 40-53, 2018.

[19] J. Ranjan and C. Foropon, "Big data analytics in building the competitive intelligence of organizations," International Journal of Information Management, vol. 56, p. 102231, 2021.

[20] J. Ranjan, "Business intelligence: Concepts, components, techniques and benefits," Journal of theoretical and applied information technology, vol. 9, no. 1, pp. 60-70, 2009.

[21] W. W. Eckerson, Performance dashboards: measuring, monitoring, and managing your business. John Wiley \& Sons, 2010.

[22] C. M. Olszak, "An overview of information tools and technologies for competitive intelligence building: theoretical approach," Issues in Informing Science and Information Technology, vol. 11, no. 1, pp. 139-153, 2014.

[23] Y. Talaoui, M. Kohtamäki, and R. Rajala, "Seeking'strategy'in business intelligence literature: Theorizing bi as part of strategy research," 2020.

[24] C. M. Olszak and J. Zurada, "Information technology tools for business intelligence development in organizations," Polish Journal of Management Studies, vol. $12,2015$.

[25] R. H. Anderson, P. S. Antón, S. C. Bankes, T. K. Bikson, and J. Caulkins, "The global course of the information revolution: Technological trends," tech. rep., RAND Corporation, 2000.

[26] M. F. Tutunea, "Business intelligence solutions for mobile devices-an overview," Procedia Economics and Finance, vol. 27, pp. 160-169, 2015.

[27] James Richardson and Kurt Schlegel, "Magic quadrant for analytics and business intelligence platforms." Accessed: 2021-05-30.

[28] R. J. Thierauf, Effective business intelligence systems. Greenwood Publishing Group, 2001.

[29] T. Ramakrishnan, J. Khuntia, A. Kathuria, and T. Saldanha, "Business intelligence capabilities and effectiveness: An integrative model," in 2016 49th Hawaii International Conference on System Sciences (HICSS), pp. 5022-5031, IEEE, 2016.

[30] O. Isik, M. C. Jones, and A. Sidorova, "Business intelligence (bi) success and the role of bi capabilities," Intelligent systems in accounting, finance and management, vol. 18, no. 4, pp. 161-176, 2011

[31] T. Grublješič and J. Jaklič, "Business intelligence acceptance: The prominence of organizational factors," Information Systems Management, vol. 32, no. 4, pp. 299-315, 2015.
[32] T. E. Yoon, B.-K. Jeong, and B. Ghosh, "User acceptance of business intelligence application: motivation to learn, technology, social influence, and situational constraints," International Journal of Business Information Systems, vol. 26, no. 4, pp. 432-450, 2017.

[33] G. Motta, T. Ma, L. You, and D. Sacco, "Delivering knowledge to the mobile enterprise implementation solutions for a mobile business intelligence," in Smart Organizations and Smart Artifacts, pp. 115-123, Springer, 2014.

[34] I. Dubravac and V. Bevanda, "Mobile business intelligence adoption (case of croatian smes)," in Proceedings of the 16th International Conference on Computer Systems and Technologies, pp. 136-143, 2015.

[35] M. Gibson, D. Arnott, I. Jagielska, and A. Melbourne, "Evaluating the intangible benefits of business intelligence: Review \& research agenda," in Proceedings of the 2004 IFIP International Conference on Decision Support Systems (DSS2004): Decision Support in an Uncertain and Complex World, pp. 295-305, Citeseer, 2004.

[36] S. Rouhani, A. Ashrafi, A. Z. Ravasan, and S. Afshari, "The impact model of business intelligence on decision support and organizational benefits," Journal of Enterprise Information Management, 2016.

[37] B. Kitchenham, "Procedures for performing systematic reviews," Keele, UK, Keele University, vol. 33, no. 2004, pp. 1-26, 2004.

[38] Scopus, "Scopus. expertly curated abstract \& citation database," 2021. Last accessed 10 June 2021.

[39] Clarivate, "Web of science. confident research begins here," 2021. Last accessed 10 June 2021.

[40] Association for Computing Machinery, "The acm guide to computing literature," 2021. Last accessed 10 June 2021.

[41] M. Gusenbauer, "Google scholar to overshadow them all? comparing the sizes of 12 academic search engines and bibliographic databases," Scientometrics, vol. 118, no. 1, pp. 177-214, 2019.

[42] E. Orduña-Malea, J. M. Ayllón, A. Martín-Martín, and E. D. López-Cózar, "Methods for estimating the size of google scholar," Scientometrics, vol. 104, no. 3, pp. 931-949, 2015.

[43] T. S. Adeyelure, B. M. Kalema, and K. J. Bwalya, "A framework for deployment of mobile business intelligence within small and medium enterprises in developing countries," Operational Research, vol. 18, no. 3, pp. 825-839, 2018.

[44] T. S. Adeyelure, B. M. Kalema, and K. J. Bwalya, "Deployment factors for mobile business intelligence in developing countries small and medium enterprises," African Journal of Science, Technology, Innovation and Development, vol. 10, no. 6, pp. 715-723, 2018.

[45] T. Peters, Ö. Işık, O. Tona, and A. Popovič, "How system quality influences mobile bi use: The mediating role of engagement," International Journal of Information Management, vol. 36, no. 5, pp. 773-783, 2016.

[46] G. Bargshady, K. Pourmahdi, P. Khodakarami, T. Khodadadi, and F. Alipanah, "The effective factors on user acceptance in mobile business intelligence," Jurnal Teknologi, vol. 72, no. 4, 2015. 
[47] Y. Buchana, The effect of mobile BI on organisational managerial decision-making. $\mathrm{PhD}$ thesis, University of Western Cape, 2014.

[48] T. Brockmann, S. Stieglitz, J. Kmieciak, and S. Diederich, "User acceptance of mobile business intelligence services," in 2012 15th International Conference on Network-Based Information Systems, pp. 861-866, IEEE, 2012.

[49] W. Hou and S. Gao, "An investigation of the managerial use of mobile business intelligence," Pacific Asia Journal of the Association for Information Systems, vol. 10, no. 3, p. 4, 2018.

[50] P. Phoobane and E. Kotzé, "The role of quality of information and intention to use in mobile business intelligence," in 2018 International Conference on Advances in Big Data, Computing and Data Communication Systems (icABCD), pp. 1-6, IEEE, 2018.

[51] L. English, "Business intelligence defined, retrieved december 20, 2007," 2005.

[52] A. Popovič, P. S. Coelho, and J. Jaklič, "The impact of business intelligence system maturity on information quality," Information research, vol. 14, no. 4, 2009.

[53] A. F. Hayes, "Process: A versatile computational tool for observed variable mediation, moderation, and conditional process modeling," 2012.

[54] A. Dillon and M. G. Morris, "User acceptance of information technology: Theories and models," Annual Review of Information Science and Technology (ARIST), vol. 31, pp. 3-32, 1996.

[55] F. D. Davis, R. P. Bagozzi, and P. R. Warshaw, "User acceptance of computer technology: A comparison of two theoretical models," Management science, vol. 35, no. 8, pp. 982-1003, 1989.

[56] J. Bradley, "If we build it they will come? the technology acceptance model," in Information systems theory, pp. 19-36, Springer, 2012.

[57] P. Legris, J. Ingham, and P. Collerette, "Why do people use information technology? a critical review of the technology acceptance model," Information \& management, vol. 40, no. 3, pp. 191-204, 2003.

[58] V. Venkatesh and F. D. Davis, "A theoretical extension of the technology acceptance model: Four longitudinal field studies," Management science, vol. 46, no. 2, pp. 186-204, 2000.

[59] R. Aggarwal, D. Kryscynski, V. Midha, and H. Singh, "Early to adopt and early to discontinue: The impact of self-perceived and actual it knowledge on technology use behaviors of end users," Information Systems Research, vol. 26, no. 1, pp. 127-144, 2015.

[60] P. Ostrowski, S. Wrycza, D. Gajda, and B. Marcinkowski, "Decision factors behind cisco networking hardware acceptance in business environments," Journal of Theoretical and Applied Electronic Commerce Research, vol. 16, no. 4, pp. 1097-1119, 2021.

[61] F. D. Davis, "Perceived usefulness, perceived ease of use, and user acceptance of information technology," MIS quarterly, pp. 319-340, 1989.

[62] E. Kaasinen, "User acceptance of mobile services: Value, ease of use, trust and ease of adoption," 2005.

[63] V. Venkatesh, M. G. Morris, G. B. Davis, and F. D. Davis, "User acceptance of information technology: Toward a unified view," MIS quarterly, pp. 425-478, 2003.
[64] U. Aggarwal and S. Bhargava, "Reviewing the relationship between human resource practices and psychological contract and their impact on employee attitude and behaviours," Journal of European Industrial Training, 2009.

[65] P. Patnasingam, D. Gefen, and P. A. Pavlou, "The role of facilitating conditions and institutional trust in electronic marketplaces," Journal of Electronic Commerce in Organizations (JECO), vol. 3, no. 3, pp. 69-82, 2005.

[66] A. Shuhaiber, "How facilitating conditions impact students' intention to use virtual lectures? an empirical evidence," in The Twelfth Advanced International Conference on Telecommunications, pp. 68-75, 2016.

[67] Y. K. Dwivedi, N. P. Rana, H. Chen, and M. D. Williams, "A meta-analysis of the unified theory of acceptance and use of technology (utaut)," in IFIP international working conference on governance and sustainability in information systems-managing the transfer and diffusion of it, pp. 155-170, Springer, 2011.

[68] Y.-S. Wang and Y.-W. Shih, "Why do people use information kiosks? a validation of the unified theory of acceptance and use of technology," Government information quarterly, vol. 26, no. 1, pp. 158-165, 2009.

[69] I. Im, S. Hong, and M. S. Kang, "An international comparison of technology adoption: Testing the utaut model," Information \& management, vol. 48, no. 1, pp. 1-8, 2011.

[70] A. B. Nassuora, "Students acceptance of mobile learning for higher education in saudi arabia," American Academic \& Scholarly Research Journal, vol. 4, no. 2, pp. 24-30, 2012.

[71] J. Kallaya, P. Prasong, and M. Kittima, "An acceptance of mobile learning for higher education students in thailand," 2009.

[72] E. M. Micheni, I. Lule, and G. M. Muketha, "Transaction costs and facilitating conditions as indicators of the adoption of mobile money services in kenya," 2013.

[73] F.-J. Molina-Castillo, C. Lopez-Nicolas, and M. de Reuver, "Mobile payment: The hiding impact of learning costs on user intentions," Journal of theoretical and applied electronic commerce research, vol. 15, no. 1, pp. 1-12, 2020.

[74] J. Woodside, "Business intelligence best practices for success," in International Conference on Information Management and Evaluation, p. 556, Academic Conferences International Limited, 2011.

[75] J. N. Montero, Determining business intelligence system usage success using the DeLone and McLean information system success model. $\mathrm{PhD}$ thesis, Capella University, 2019.

[76] M. Kowalczyk and J. P. Gerlach, "Business intelligence $\&$ analytics and decision quality-insights on analytics specialization and information processing modes," 2015.

[77] B. Wieder, M. Ossimitz, and P. Chamoni, "The impact of business intelligence tools on performance: a user satisfaction paradox?," International Journal of Economic Sciences and Applied Research, vol. 5, no. 3, pp. 7-32, 2012.

[78] J. Koetsier, "There are now 8.9 million mobile apps, and china is 40 percent of mobile app spending," 2020.

[79] J. O'Halloran, "Mobile business and productivity apps see 7.1 billion downloads in 2020," 2020. 